\title{
Ten Years of Results of Modified Frontalis Muscle Transfer for the Correction of Blepharoptosis
}

\author{
Woo Jeong Kim, Dae Hwan Park, Dong Gil Han \\ Department of Plastic and Reconstructive Surgery, School of Medicine, Catholic University of Daegu, Daegu, Korea
}

Background Conventional frontalis transfer may cause a range of complications. In order to overcome complications, we made modifications to the surgical technique, and compared the outcomes of patients who underwent conventional frontalis transfer with those of patients who underwent modified frontalis transfer.

Methods We conducted a retrospective study of 48 patients (78 eyes) who underwent conventional frontalis transfer between 1991 and 2003 (group A) and 67 patients (107 eyes) who underwent modified frontalis transfer between 2004 and 2014 (group B). The frontalis transfer procedures were modified conform to the following principles. The tip of the frontalis muscle flap included soft tissue that was as thick as possible and the soft tissue on the tarsal plate was removed to the greatest extent possible. A double fold was created in cases of unilateral ptosis. In order to evaluate the objective effects of modification, preoperative and postoperative values of the marginal distance reflex 1 (MRD1), the corneal exposure area, and the decrease in eyebrow height were compared between the two groups.

Results In group A, patients showed an improvement of $1.19 \mathrm{~mm}$ in the MRD1, a 6.31\% improvement in the corneal exposure area, and a $7.82 \mathrm{~mm}$ decrease in eyebrow height. In group B, patients showed an improvement of $2.17 \mathrm{~mm}$ in the MRD1, an 8.39\% improvement in the corneal exposure area, and an $11.54 \mathrm{~mm}$ decrease in eyebrow height. The improvements in group B were significantly greater than those in group A.

Conclusions Modified frontalis transfer showed better results than the conventional procedure and provided satisfactory outcomes.

Keywords Blepharoplasty / Blepharoptosis / Facial muscle

\author{
Correspondence: Dong Gil Han \\ Department of Plastic and \\ Reconstructive Surgery, School of \\ Medicine, Catholic University of \\ Daegu, Duryugongwon-ro 17-gil, \\ Nam-gu, Daegu 42472, Korea \\ Tel: +82-53-650-4474 \\ Fax: + 82-53-650-4584 \\ E-mail:dghan1001@cu.ac.kr
}

This article was presented as a free paper at the 72 nd Congress of the Korean Society of Plastic and Reconstructive Surgeons on November 7, 2014 in Seoul, Korea.

No potential conflict of interest relevant to this article was reported.

Received: 18 Jul 2015 • Revised: 12 Jan 2016 • Accepted: 7 Feb 2016

pISSN: 2234-6163 • elSSN: 2234-6171 • http://dx.doi.org/10.5999/aps.2016.43.2.172 • Arch Plast Surg 2016;43:172-180

\section{INTRODUCTION}

Surgical techniques using the frontalis muscle have been frequently applied to patients with blepharoptosis, particularly those with poor $(\leq 4 \mathrm{~mm})$ levator palpebrae muscle function [1]. The frontalis myofascial flap, the superiorly based orbicularis oculi muscle flap [2], and frontalis transfer are examples of surgical techniques using the frontalis muscle. Frontalis transfer, first reported by Song and Song [3], is an excellent technique that can be applied in the management of severe ptosis, and many others have used frontalis transfer to correct blepharoptosis. However, we performed more than 10 years of follow-up on patients who underwent correction by frontalis transfer in our department, and observed complications including the recur- 
rence of ptosis, undercorrection, hematoma, ectropion or entropion, and asymmetry. Without any special modifications, the complication rate of the conventional frontalis transfer method, was determined to be as high as $20 \%$.

Therefore, we implemented several modifications of the frontalis transfer method to overcome those complications. The outcomes between the conventional frontalis transfer group and the modified frontalis transfer group were compared to clarify the efficacy of our modifications to the frontalis muscle transfer technique.

\section{METHODS}

\section{Patients and preoperative evaluation}

This was a retrospective comparative study including 115 patients with moderate to severe ptosis who were treated from 1991 through 2014. The patients were classified into two groups: those who underwent frontalis transfer from 1991 to 2003 (group A, $\mathrm{n}=78$ eyes in 48 patients) and those who underwent the modified frontalis transfer from 2004 to 2014 (group B, n= 107 eyes in 67 patients). We began performing the modified frontalis transfer procedure in 2004. All operations were performed by the senior author (D.H.P).

In group A, 11 eyes exhibited mild ptosis, 26 eyes displayed moderate ptosis, and 41 eyes had severe ptosis. In contrast, in group B, three eyes showed mild ptosis, 28 eyes exhibited moderate ptosis, and 76 eyes displayed severe ptosis. In group A, the patients were 3-73 years of age and included 37 men and 11 women. A total of 78 eyes were evaluated in this group. Thirty patients ( 60 eyes) had bilateral ptosis, whereas 18 patients (18 eyes) had unilateral ptosis. In Group B, the patients ranged from 11 to 76 years of age, including 39 men and 28 women. A total of 107 eyes were evaluated in this group. Forty patients ( 80 eyes) had bilateral ptosis, while 27 patients ( 27 eyes) had unilateral ptosis.

Each patient's history was taken carefully. Before surgery, all patients were asked to provide demographic information, including age, sex, whether the ptosis was unilateral or bilateral, and the etiology of the ptosis. In order to compare the surgical results of group A and group B objectively, the marginal reflex distance1 (MRD1), corneal exposure area (CEA), and eyebrow height were examined based on photographs taken before and after surgery (Table 1). In addition, starting in 2014, platelet function analysis (PFA) was checked in order to assess patients' tendency to bleed [4].

The MRD1 was examined using photographs of the patient taken before and after surgery, using the ruler tool in Adobe Photoshop CS3 (Adobe Systems, San Francisco, CA, USA). The
Table 1. Patient demographics and physical examination findings

\begin{tabular}{|lcc|}
\hline Dermographics & Group A & Group B \\
\hline No. of patients (no. of eyelids) & $48(78)$ & $67(107)$ \\
Age (yr) & $22.4 \pm 13.3$ & $35.7 \pm 16.8$ \\
Sex (male/female) & $37 / 11$ & $39 / 28$ \\
Severity of ptosis (no. of eyelids) & & \\
Mild (<2 mm) & 11 & 3 \\
Moderate (2-4 mm) & 26 & 28 \\
Severe (>4 mm) & 41 & 76 \\
\hline Values are presented as mean \pm standard deviation. \\
\hline
\end{tabular}

CEA was calculated using the value of the total eyeball area and the area of the iris and pupil, and qualitatively analyzed using a Java-based image processing program (Image J 1. 40, National Institutes of Health, Bethesda, MD, USA). Using the measurement software, the CEA was measured independently by two examiners. First, the exposed area of the iris \& pupil area and the total corneal area was measured by using Adobe Photoshop. Second, the area of quantification was measured by using Image $\mathrm{J}$, and the percentage of the exposed area of the iris \& pupil taken up by the total cornea area(exposed iris and pupil/total cornea area $\times 100$ ) was calculated by Image J. A horizontal line was drawn passing from the medial canthus through the pupil and to the lateral canthus. From this horizontal line, three vertical lines were drawn perpendicularly. Eyebrow height was measured by defining the lengths between the upper margin of the eyebrow and the lateral canthus ( $\mathrm{H} 1)$, pupil $(\mathrm{H} 2)$, and medial canthus (H3), which were measured using the ruler tool of Adobe Photoshop CS3 (Adobe Systems, San Francisco, CA, USA) [5]. Ideal corrections were defined according to the guidelines developed by Souther et al. [6] and Jordan and Anderson [7], which recommend placement of the upper eyelid margin just below the upper border of the limbus at the primary position in bilateral cases.

The, MRD1 and CEA were compared between the two treatment groups by subtracting the preoperative values from the postoperative values. The eyebrow heights $(\mathrm{H} 1, \mathrm{H} 2$, and $\mathrm{H} 3$ ) were compared by subtracting the postoperative values from the preoperative values. Postoperative photographs were taken six months after surgery, to minimize observational errors due to time and postoperative swelling. In order to minimize errors caused by differences in size of photograph, the corneal diameter was measured for each patient and corrected using the average corneal diameter in Koreans. The average corneal diameter of Korean females has been found to be $11.3 \mathrm{~mm}$, while that of Korean males has been found to be $11.6 \mathrm{~mm}$. Corrected eyebrow heights and corneal diameters were entered in Microsoft Excel (Microsoft, Seattle, WA, USA). Thus, errors caused by 
Fig. 1. Intraoperative photographs of modified frontalis transfer

(A) The frontalis muscle flap was elevated to be as thick as possible. (B) The soft tissue on the tarsal plate was removed as much as possible.
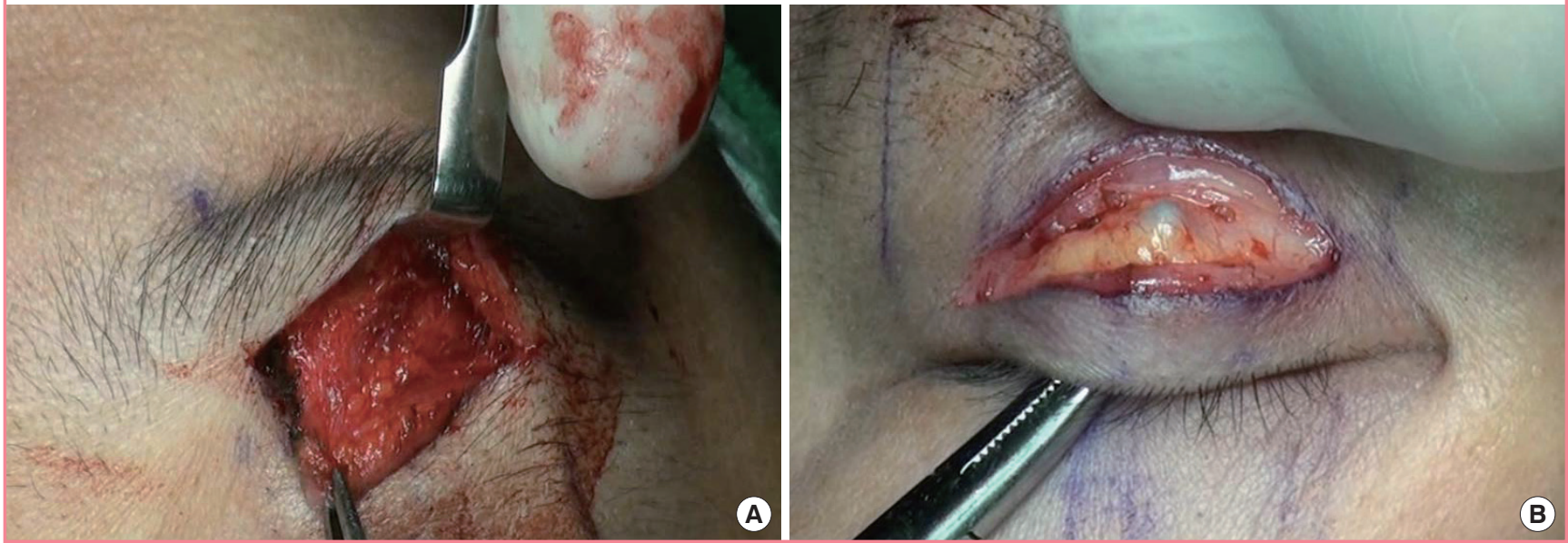

Fig. 2. Intraoperative photograph after tunneling of the muscle flap

The frontalis muscle flap was passed through a small tunnel from behind the orbital septum.

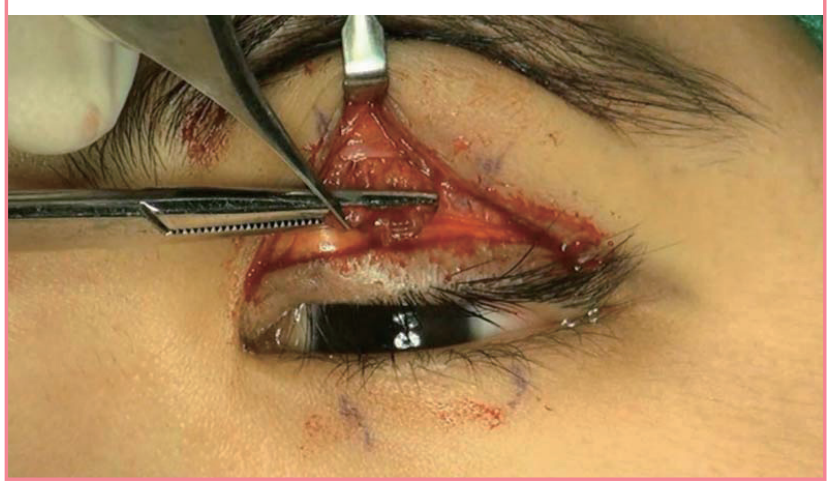

differences in proportions were minimized [8].

Statistical analysis was performed using SPSS ver. 19.0 (IBM Co., Armonk, NY, USA). In both groups, the preoperative and postoperative measurements of the MRD1, CEA, and eyebrow height were compared using the two-sample t-test. P-values $<0.05$ were considered to indicate statistical significance.

\section{Surgical procedures of modified frontalis transfer}

Only 13 patients underwent surgery under general anesthesia. The remaining 54 patients underwent surgery under local anesthesia using 2\% lidocaine $\mathrm{HCl}$ combined with 1:100,000 epinephrine. Incision lines were drawn directly under the eyebrow, in order to avoid the supraorbital foramen where the supraorbital nerve originates, followed by incisions applied diagonally in order to avoid damage to hair follicles. Through this incision, the skin was dissected superiorly along the subcutaneous tissue layer, exposing the frontalis muscle. The frontalis muscle was el-
Fig. 3. Preoperative design for a symmetrical supratarsal crease

We performed surgery to create a double fold along a line drawn symmetrically to the contralateral eyelid in cases of unilateral ptosis.

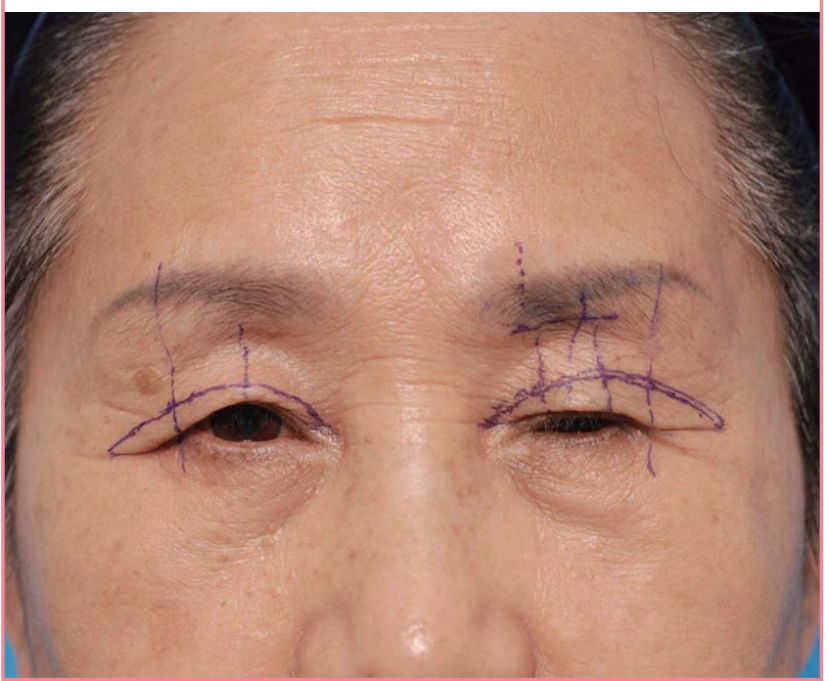

evated from the periosteum by applying a horizontal incision into the frontalis muscle to the level directly superior to the periosteum, followed by a $13 \mathrm{~cm}$ vertical incision on the medial side of the frontalis muscle, on the lateral side of the supraorbital notch. We attempted to thicken the flap by obtaining as much soft tissue as possible, and also excised the soft tissue that laid over the tarsal plate to the greatest extent possible (Fig. 1). An incision was made after the preoperative design, where the double eyelid would be made. The frontalis muscle was passed through the incision after the skin was dissected posteriorly to the orbital septum (Fig. 2). The frontalis muscle, which passed through and was fixed to the tarsal plate with PDS 6-0 sutures, was overcorrected by approximately $12 \mathrm{~mm}$. After fixation of the 
frontalis muscle to the tarsal plate in cases of unilateral ptosis, we performed surgery creating a double fold along an eyelid line drawn symmetrically to the contralateral eyelid (Fig. 3). Finally, the subcutaneous tissue and skin were sutured using vicryl 6-0 and nylon 6-0 sutures, respectively. Patients found to have a high likelihood of bleeding by preoperative PFA [4] underwent thorough hemostasis during surgery and drainage tubes were inserted (Fig. 4), followed by compressive dressing. Drainage tubes were removed within 24 hours to 48 hours if no particular problems were noted (Table 2) [9].

\section{Fig. 4. Immediate postoperative photograph of a patient} with a tendency for bleeding

A drainage tube was inserted, followed by a compressive dressing, and was maintained for one day.

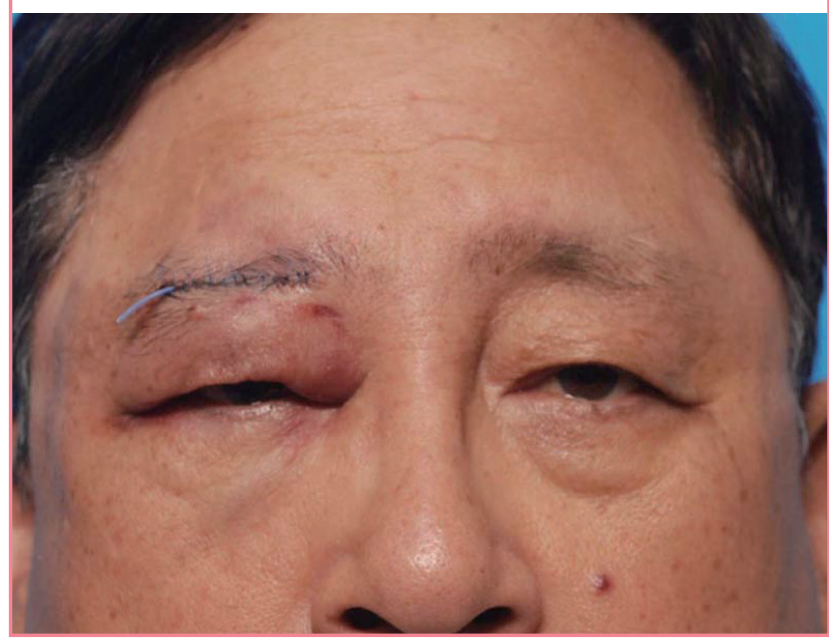

Table 2. Modifications in the method introduced in this study

\begin{tabular}{l}
\hline \multicolumn{1}{|c|}{ Modifications } \\
\hline 1. The frontalis muscle flap must include soft tissues that are as thick as possible. \\
2. The soft tissue on the tarsal plate must be removed to the greatest extent \\
possible. \\
$\begin{array}{l}\text { 3. The frontalis flap is passed through a small tunnel above the orbital fat. } \\
\text { 4. Double eyelid plasty on the unaffected eyelid is performed in cases of unilateral } \\
\text { ptosis. }\end{array}$ \\
\hline
\end{tabular}

\section{RESULTS}

In the preoperative evaluations of the 78 eyes in group $\mathrm{A}$, the mean MRD1 was $0.3 \mathrm{~mm}$, while the mean MRD1 value six months after surgery was $1.49 \mathrm{~mm}$, showing an improvement of $1.19 \pm 0.91 \mathrm{~mm}$ after surgery. In the preoperative evaluations of group B, the mean MRD1 of 107 eyes was $0.21 \mathrm{~mm}$, while the mean MRD1 value six months after surgery was $1.96 \mathrm{~mm}$, showing an improvement of $2.17 \pm 1.19 \mathrm{~mm}$ after surgery $(\mathrm{P}<0.001)$ (Table 3).

The mean preoperative CEA value of the 78 eyes in group A, was $63.12 \%$, which increased to $69.43 \%$ postoperatively, showing an improvement of approximately $6.31 \% \pm 0.55 \%$. In group $\mathrm{B}$, the mean preoperative value of 107 eyes was $63.11 \%$, increasing to $71.51 \%$ postoperatively, showing an improvement of approximately $8.39 \% \pm 1.14 \%(\mathrm{P}<0.001)$ (Table 4$)$.

The preoperative eyebrow height measurements of the 78 eyes in group A were $31.07 \mathrm{~mm}$ for $\mathrm{H} 1,33.95 \mathrm{~mm}$ for $\mathrm{H} 2$, and 30.26 $\mathrm{mm}$ for $\mathrm{H} 3$. The postoperative values were, $23.39 \mathrm{~mm}, 25.86$ $\mathrm{mm}$, and $22.57 \mathrm{~mm}$, respectively, showing a mean decrease of approximately $7.68 \pm 1.71 \mathrm{~mm}$ for $\mathrm{H} 1,8.09 \pm 3.37 \mathrm{~mm}$ for $\mathrm{H} 2$,

Table 3. Improvements in marginal reflex distance 1 (MRD1)

\begin{tabular}{|lcrc|}
\hline Degree of MRD1 (mm) & Group A & Group B & P-value $^{\text {a) }}$ \\
\hline Preoperative MRD1 & $0.30 \pm 1.1$ & $-0.21 \pm 1.19$ & - \\
Postoperative MRD1 & $1.49 \pm 0.80$ & $1.96 \pm 0.50$ & - \\
Improvement & $1.19 \pm 0.91$ & $2.17 \pm 1.19$ & $<0.001$ \\
\hline $\begin{array}{l}\text { Values are presented as mean } \pm \text { standard deviation. } \\
\text { a)Two-sample t-test. }\end{array}$ \\
\hline
\end{tabular}

Table 4. Improvements in the corneal exposure area (CEA)

\begin{tabular}{|lcrc|}
\hline CEA (\%) & Group A & Group B & P-value ${ }^{\text {a) }}$ \\
\hline Preoperative CEA & $63.12 \pm 4.54$ & $63.11 \pm 4.32$ & - \\
Postoperative CEA & $69.43 \pm 4.93$ & $71.51 \pm 4.77$ & - \\
Improvement & $6.31 \pm 0.55$ & $8.39 \pm 1.14$ & $<0.001$ \\
\hline $\begin{array}{l}\text { Values are presented as mean } \pm \text { standard deviation. } \\
\text { a)Two-sample t-test. }\end{array}$ & & \\
\hline
\end{tabular}

Table 5. Changes in eyebrow height $(\mathrm{mm})$

\begin{tabular}{|c|c|c|c|c|c|c|c|}
\hline \multirow{2}{*}{ Measurement point } & \multicolumn{3}{|c|}{ Group A } & \multicolumn{3}{|c|}{ Group B } & \multirow{2}{*}{ P-value ${ }^{a)}$} \\
\hline & $\mathrm{H} 1$ & $\mathrm{H} 2$ & H3 & $\mathrm{H} 1$ & $\mathrm{H} 2$ & H3 & \\
\hline Preoperative eyebrow height & $31.07 \pm 3.62$ & $33.95 \pm 3.96$ & $30.26 \pm 3.80$ & $31.33 \pm 3.44$ & $32.76 \pm 3.51$ & $30.22 \pm 4.47$ & - \\
\hline Postoperative eyebrow height & $23.39 \pm 3.76$ & $25.86 \pm 4.94$ & $22.57 \pm 3.56$ & $19.56 \pm 3.17$ & $21.20 \pm 3.17$ & $18.95 \pm 3.19$ & - \\
\hline Change (preoperative-postoperative) & $7.68 \pm 1.71$ & $8.09 \pm 3.37$ & $7.69 \pm 1.59$ & $11.77 \pm 2.63$ & $11.56 \pm 2.85$ & $11.3 \pm 3.82$ & $<0.001$ \\
\hline
\end{tabular}

Values are presented as mean \pm standard deviation.

$H 1$, lateral eyebrow height; $H 2$, central eyebrow height; $H 3$, medial eyebrow height.

a)Two-sample t-test. 
and $7.69 \pm 1.59 \mathrm{~mm}$ for $\mathrm{H} 3$ and a mean decrease of $7.82 \mathrm{~mm}$ averaged over all three sets of measurements. The preoperative eyelid heights of the 107 eyes in group B were $31.33 \mathrm{~mm}$ for $\mathrm{H} 1$, $32.76 \mathrm{~mm}$ for $\mathrm{H} 2$, and $30.22 \mathrm{~mm}$ for $\mathrm{H} 3$. The postoperative values were $19.56 \mathrm{~mm}$ for $\mathrm{H} 1,21.20 \mathrm{~mm}$ for $\mathrm{H} 2$, and $18.95 \mathrm{~mm}$ for $\mathrm{H} 3$, showing average decreases of approximately $11.77 \pm 2.63$ $\mathrm{mm}, 11.56 \pm 2.85 \mathrm{~mm}$, and $11.3 \pm 3.82 \mathrm{~mm}$, respectively. The mean change averaged over all three sets of measurements was $11.54 \mathrm{~mm}(\mathrm{P}<0.001)$ (Table 5). The changes before and after surgery in the MRD1, CEA, and eyebrow height were all statistically significant $(\mathrm{P}<0.001)$.

The complications in group A were six undercorrections (7.7\%), three overcorrections (3.8\%), two cases of fold asymmetry (2.6\%), two cases of abnormal eyelid contour (2.6\%), and two hematomas (2.6\%). The overall rate of complications in group A was $19.3 \%$. Revision surgery was performed for two undercorrections, one overcorrection, and one fold asymmetry. The complications in group B were three undercorrections (2.8\%), one case of fold asymmetry ( $0.9 \%)$, two cases of abnormal eyelid contour $(1.9 \%)$, and one hematoma ( $0.9 \%)$. The overall rate of complications in group B was $6.5 \%$. Revision surgery was per-

\section{Table 6. Postoperative complications}

\begin{tabular}{|lcc|}
\hline Complication & Group A & Group B \\
\hline Undercorrection & $6(7.7)$ & $3(2.8)$ \\
Overcorrection & $3(3.8)$ & 0 \\
Fold asymmetry & $2(2.6)$ & $1(0.9)$ \\
Abnormal eyelid contour & $2(2.6)$ & $2(1.9)$ \\
Hematoma & $2(2.6)$ & $1(0.9)$ \\
Total & $15(19.2)$ & $7(6.5)$ \\
\hline Values are presented as number (\%). & \\
\hline
\end{tabular}

formed for one undercorrection and one fold asymmetry. In comparison with group $\mathrm{A}$, which showed complications in 15 cases out of 78 eyes (19.2\%), group B showed complications in seven cases out of 107 eyes (6.5\%), which was a much lower rate of complications (Table 6).

\section{DISCUSSION}

The frontalis transfer technique was first reported by Song and Song [3]. Conventional frontalis transfers cause lagophthalmos in most cases, while also leading to complications such as recurrence (Fig. 5), under correction (Fig. 6), ectropion and entropion, asymmetry, and hematoma. In our analysis of 48 patients from 1991 to 2003, the complications included three undercorrections $(2.8 \%)$, one case of fold asymmetry $(0.9 \%)$, two cases of abnormal eyelid contour (1.9\%), and one hematoma ( $0.9 \%)$, with a complication rate of $19.2 \%$.

In order to reduce the incidence of such complications, we made several surgical modifications.

First we made a thick frontalis muscle flap, containing as much soft tissue as possible, in order to facilitate firm fixation and to reduce the possibility of under correction or recurrence. Second, the soft tissue at the tarsal plate was removed to the greatest extent possible in order to make a better attachment and to avoid eventual loosening between the flap and the tarsal plate. Third, a small passage was made posteriorly to the orbital septum, changing the direction of movement tangentially to prevent ectropion or entropion. With regard to using the orbital septum as an axis for changing the direction of the frontalis, this procedure may use the same concept as that of the technique reported by Ramirez and Pena [10]. However, Ramirez and Pena dissected the

\section{Fig. 5. A 47-year-old man with unilateral severe ptosis}

(A) Preoperative photograph. The marginal reflex distance 1 (MRD1) of the left eye was $0.4 \mathrm{~mm}$, his corneal exposure area was $29.8 \%$, and his eyebrow height measurements $(\mathrm{H} 1, \mathrm{H} 2$, and $\mathrm{H} 3)$ were $42.64 \mathrm{~mm}, 39.57 \mathrm{~mm}$, and $37.45 \mathrm{~mm}$, respectively. (B) A photograph taken six months after conventional frontalis transfer, showing recurrence. The postoperative MRD1 of the left eye was $1 \mathrm{~mm}$, the corneal exposure area was $43.5 \%$, and his eyebrow height measurements ( $\mathrm{H} 1, \mathrm{H} 2$, and $\mathrm{H} 3$ ) were $38.77 \mathrm{~mm}, 36.54 \mathrm{~mm}$, and $34.12 \mathrm{~mm}$, respectively.
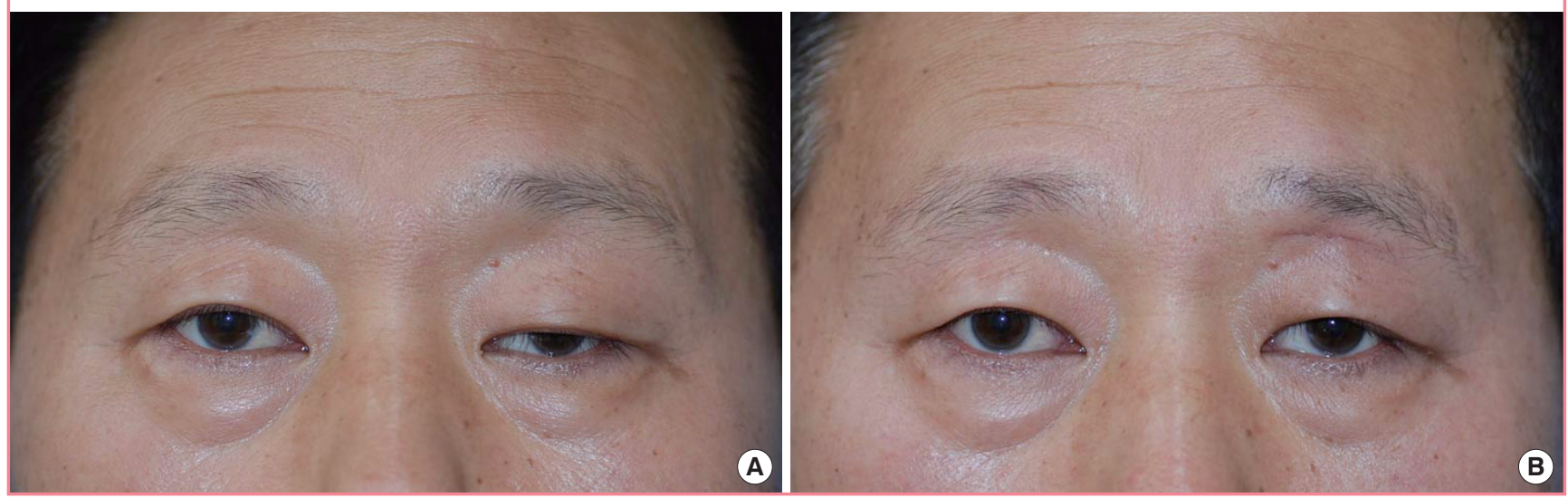
Fig. 6. An 18-year-old man with bilateral severe ptosis

(A) Preoperative photograph. The marginal reflex distance (MRD1) of his right eye was $0 \mathrm{~mm}$, the corneal exposure area was $48.7 \%$, and the eyebrow height measurements $(\mathrm{H} 1, \mathrm{H} 2$, and $\mathrm{H} 3)$ were $32.32 \mathrm{~mm}, 33.65 \mathrm{~mm}$, and $34.74 \mathrm{~mm}$, respectively. The MRD1 of his left eye was $0 \mathrm{~mm}$, the corneal exposure area was 48.5\%, and the eyebrow height measurements ( $\mathrm{H} 1, \mathrm{H} 2$, and $\mathrm{H} 3)$ were $33.12 \mathrm{~mm}, 34.55 \mathrm{~mm}$, and $35.38 \mathrm{~mm}$, respectively. (B) A photograph taken six months after conventional frontalis transfer showing undercorrection. The postoperative MRD1 of the right eye was $2.2 \mathrm{~mm}$, the corneal exposure area was 72.2\%, and the eyebrow height measurements $(\mathrm{H} 1, \mathrm{H} 2$, and $\mathrm{H} 3)$ were $29.92 \mathrm{~mm}, 29.91 \mathrm{~mm}$, and $32.54 \mathrm{~mm}$, respectively. The postoperative MRD1 of the left eye was $2.1 \mathrm{~mm}$, the corneal exposure area was 73.5\%, and the eyebrow height measurements $(\mathrm{H} 1, \mathrm{H} 2$, and $\mathrm{H} 3)$ were $29.85 \mathrm{~mm}, 29.74 \mathrm{~mm}$, and $30.65 \mathrm{~mm}$, respectively.
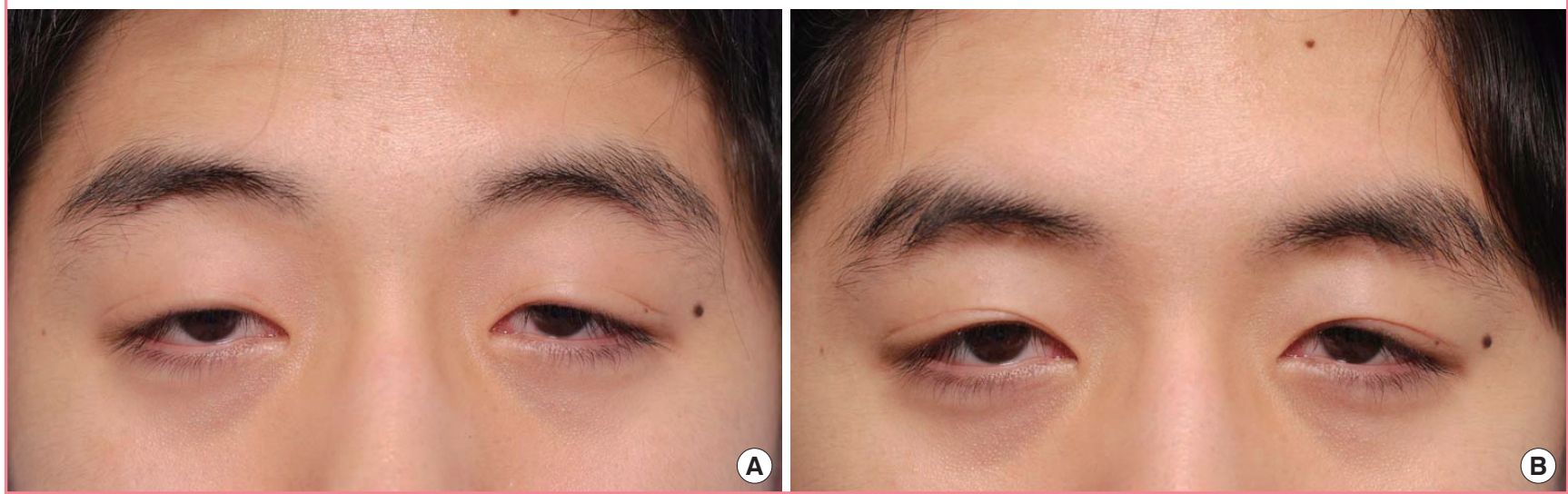

Fig. 7. A 32-year-old man with unilateral severe ptosis

(A) Preoperative photograph. The marginal reflex distance 1 (MRD1) of the left eye was $0.4 \mathrm{~mm}$, the corneal exposure area was $35.2 \%$, and the eyebrow height measurements $(\mathrm{H} 1, \mathrm{H} 2$, and $\mathrm{H} 3$ ) were $42.85 \mathrm{~mm}, 43.75 \mathrm{~mm}$, and $38.22 \mathrm{~mm}$, respectively. (B) A photograph taken six months after modified frontalis transfer. The postoperative MRD1 of the left eye was $2.5 \mathrm{~mm}$, the corneal exposure area was $79.2 \%$, and the eyebrow height measurements $(\mathrm{H} 1, \mathrm{H} 2$, and $\mathrm{H} 3)$ were $32.32 \mathrm{~mm}, 31.25 \mathrm{~mm}$, and $28.64 \mathrm{~mm}$, respectively. Mild lagophthalmos was observed in the closed eye view, but, may be expected to improve as result of skin loosening with the passage of time.
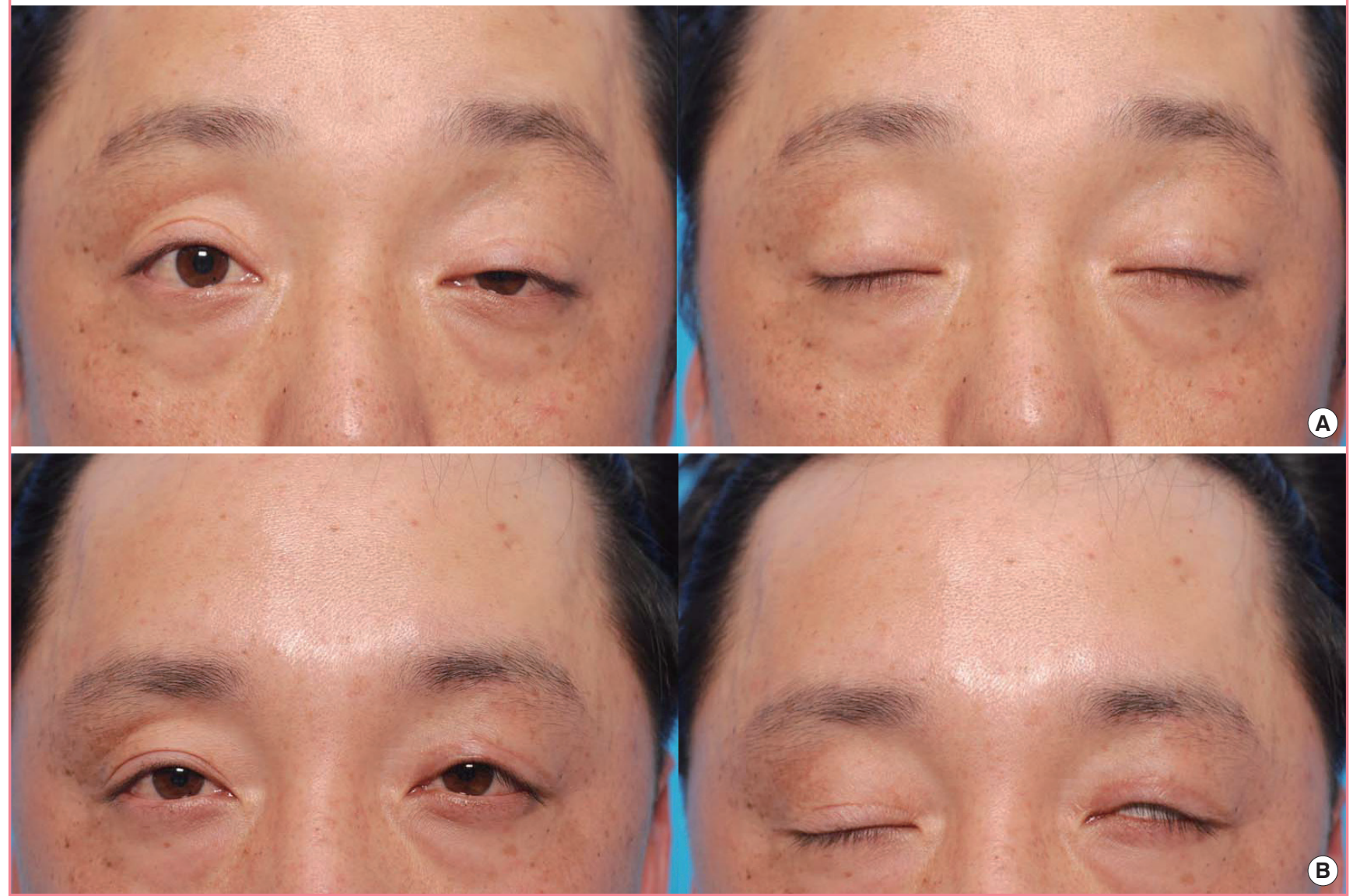


\section{Fig. 8. A 20-year-old woman with bilateral severe ptosis}

(A) Preoperative photograph. The marginal reflex distance 1 (MRD1) of the right eye was $0.52 \mathrm{~mm}$, the corneal exposure area was $60.3 \%$, and the eyebrow height measurements $(\mathrm{H} 1, \mathrm{H} 2$, and $\mathrm{H} 3$ ) were $36.62 \mathrm{~mm}, 35.43 \mathrm{~mm}$, and $34.27 \mathrm{~mm}$, respectively. The MRD1 of her left eye was $0.7 \mathrm{~mm}$, the corneal exposure area was 62.5\%, and the eyebrow height measurements ( $\mathrm{H} 1, \mathrm{H} 2$, and $\mathrm{H} 3$ ) were $36.52 \mathrm{~mm}, 35.55 \mathrm{~mm}, 35.38 \mathrm{~mm}$. (B) A photograph taken six months and two weeks after modified frontalis transfer. The postoperative MRD1 of the right eye was $2.8 \mathrm{~mm}$, the corneal exposure area was 78.2\%, and the eyebrow height measurements ( $\mathrm{H} 1, \mathrm{H} 2$, and $\mathrm{H} 3$ ) were $29.54 \mathrm{~mm}, 29.42 \mathrm{~mm}$, and $26.85 \mathrm{~mm}$, respectively. The postoperative MRD1 of the left eye was $2.8 \mathrm{~mm}$, the corneal exposure area was $77.8 \%$, and the eyebrow height measurements ( $\mathrm{H} 1$, $\mathrm{H} 2$, and $\mathrm{H} 3$ ) were $29.58 \mathrm{~mm}, 29.45 \mathrm{~mm}$, and $26.88 \mathrm{~mm}$, respectively. Lagophthalmos was not observed in the closed eye view.
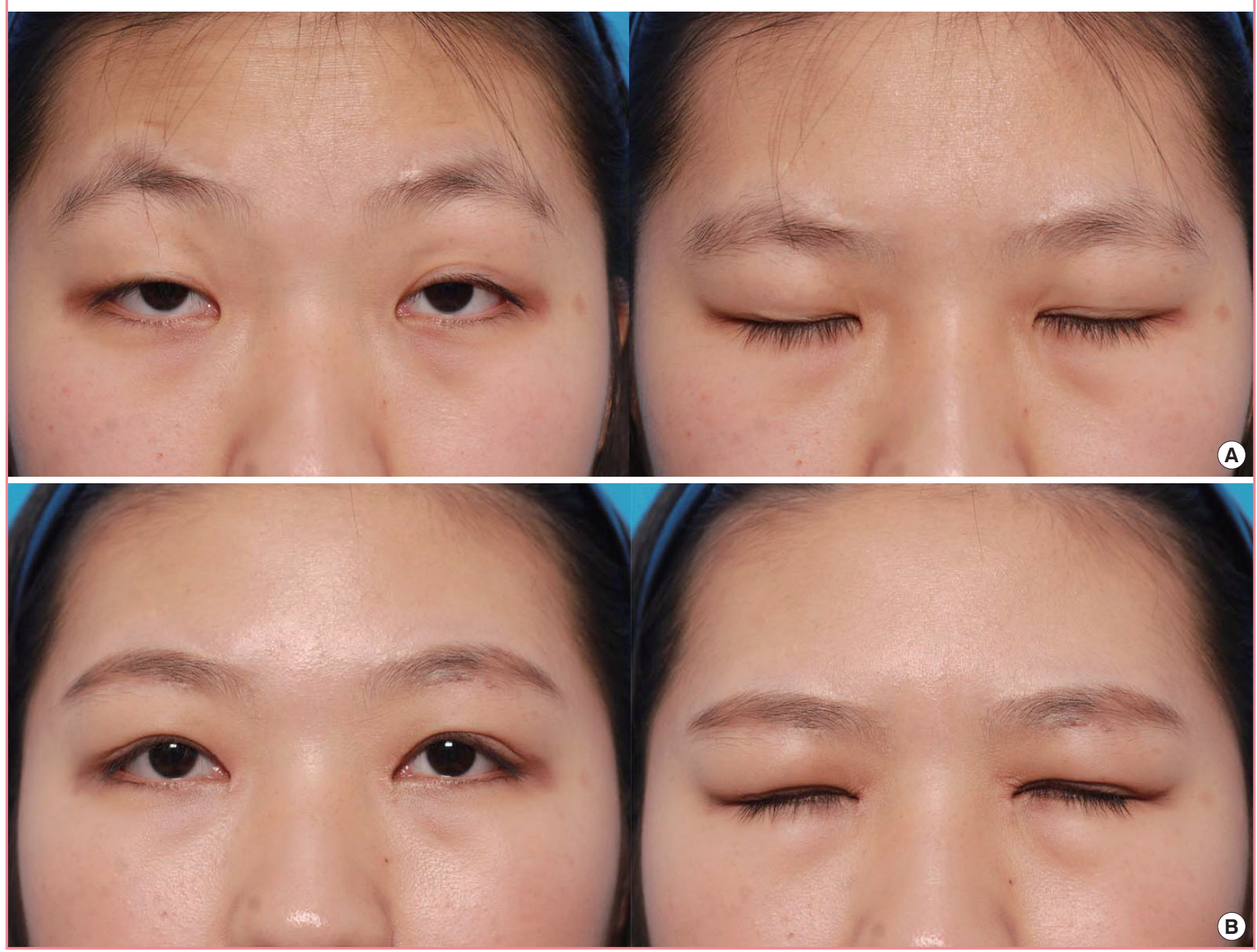

orbital septum by making incisions superior to the orbit, which differs from our technique, in which an incision was made along the upper eyebrow, exposing the orbital septum, and dissecting it by incisions. Modifications such as a technique reported by Vasquez et al. [11], in which the levator aponeurosis is used as an axis and the direction of the frontalis is changed less tangentially, have recently been introduced. Fourth, a double-fold operation or upper blepharoplasty including skin excision was performed on the contralateral eyelid in order to ensure fold height symmetry in cases of unilateral ptosis. Additionally, patients with bilateral ptosis were asked to sit up during surgery to determine whether symmetry was achieved, and the vertical palpebral fissure height was checked several times in sitting and lying positions to evaluate the symmetry. In addition, we attempted to minimize hematoma formation by performing a preoperative PFA evaluation, as well as by referring to a patient's history and through strict hemostasis, drainage tube insertion, and the use of a postoperative compressive dressing.

In our analysis of 67 patients who underwent the above described modified surgical procedures from 2004 to 2014, the complications were three undercorrections $(2.8 \%)$, one case of fold asymmetry (0.9\%), two cases of abnormal eyelid contour (1.9\%), and one hematoma (0.9), with an overall complication rate of $6.5 \%$. Satisfactory results were obtained in comparison to the outcomes of the patients who underwent conventional frontalis transfer. 
Moreover, by comparing the preoperative and postoperative photographs, we observed improvements in postoperative MRD1 and CEA values. The postoperative CEA values were similar to the value obtained from 167 physically normal people without a history of eyelid surgery, eye trauma, or diseases of the eye who were examined at our hospital $(75.4 \% \pm 2 \%)$. Postoperative eyebrow height values decreased to the point that they were lower than the values reported by Kim et al. [5] from 12 physically normal people with 24 normal eyebrows (H1, $26.44 \mathrm{~mm}$; H2, $28.3 \mathrm{~mm}$; and H3, $25.71 \mathrm{~mm}$ ). Thus, we observed clear decreases in eyebrow height after frontalis transfer. In the patients who underwent modified frontalis transfer, all measured changes (MRD1, CEA, and eyebrow height) were statistically significant.

Early complications included overcorrection, undercorrection, asymmetry, and so forth, but these complications resolved with the passage of time, leaving no permanent complications (Figs. $7,8)$. Lagophthalmos occurred in almost all patients who underwent frontalis transfer. We therefore applied eye drops as well as ointment and taping during sleep, and referred the patients to an ophthalmologist if other ocular problems persisted. The authors followed up the patients for six months, and almost all cases of lagophthalmos had resolved. The scars made directly under the eyebrow also resolved easily.

Postoperative changes in the MRD1 and eyebrow height are generally recognized to be useful values for evaluating ptosis correction $[5,12]$. The CEA, devised by the authors, is also a useful measurement in that it evaluates the extent of the cornea covered by the eyelid. Measurements using digital images were proven to be useful by Choi et al. [13] and Flynn et al. [14]. However, digital measurements have limitations due to the effects of posture and distance when taking photographs, particular, measurement errors are possible between the clinical MRD1 and the photographic MRD1 due to non-coaxial light source in the upright position with dSLR-pop and the frontalis muscle reaction, which can prevented by using a slit-lamp mounted digital photography system with the head resting against the brow $[13$, 15]. Thus, the author prepared a separate studio space with a consistent light source, and used the same chair, camera, and aperture in order to reduce such errors as much as possible. Since these conditions were met, the digital images may be expected to have values that are very similar to clinical measurements.

The drawbacks of our technique include the fact that a learning curve is required for decision-making, selection of the surgical technique, and the modification of surgical skills. Moreover, it is difficult to apply these procedures to young patients because of their lower cooperation, also difficult to general anesthesia patients. Therefore, precise preoperative designing through repetitive measurements is required for young patients or those with a lower degree of cooperation [16].

In conclusion, skillful techniques that enable precise dissection and minimize bleeding, as well as a thorough knowledge of the exact insertion site of the frontalis muscle [17] and of anatomical structures might be helpful in overcoming the potential limitations of this procedure.

\section{REFERENCES}

1. Beard C. Examination and evaluation of the ptosis patient. In: Smith BC, Nesi FA, Levine MR, et al., editors. Smith's ophthalmic plastic and reconstructive surgery. 2 nd ed. St. Louis, MO: Mosby; 1998. p.339-58.

2. Park DH, Ahn KY, Han DG, et al. Blepharoptosis repair by selective use of superiorly based muscle flaps. Plast Reconstr Surg 1998;101:592-603.

3. Song R, Song Y. Treatment of blepharoptosis: direct transplantation of the frontalis muscle to the upper eyelid. Clin Plast Surg 1982;9:45-8.

4. Han J, Do ER, Kim TS, et al. Clinical application and evaluation of preoperative bleeding tendency using platelet function analyzer (PFA(R))-100. Arch Aesthetic Plast Surg 2013; 19:56-63.

5. Kim TS, Han DG, Do ER, et al. The change of eyebrow height after blepharoptosis correction. Arch Aesthetic Plast Surg 2013;19:46-50.

6. Souther SG, Corboy JM, Thompson JB. The Fasanella-Servat operation for ptosis of the upper eyelid. Plast Reconstr Surg 1974;53:123-8.

7. Jordan DR, Anderson RL. The aponeurotic approach to congenital ptosis. Ophthalmic Surg 1990;21:237-44.

8. Bae TH, Kim JC, Kim WS, et al. A photogrammetic study of the eyes in Korean youths.J Korean Soc Plast Reconstr Surg 2007;34:37-43.

9. Park DH, Lee SJ, Song CH. Recurrence of blepharoptosis after a superiorly based muscle flap: treatment by frontalis muscle advancement. Plast Reconstr Surg 2005;116:1954-9.

10. Ramirez OM, Pena G. Frontalis muscle advancement: a dynamic structure for the treatment of severe congenital eyelid ptosis. Plast Reconstr Surg 2004;113:1841-9.

11. Vasquez LM, Alonso T, Medel R. Direct frontalis flap with and without levator pulley for correction of severe ptosis with poor levator function in the same patient. Orbit 2012;31: 102-6.

12. Callahan MA, Beard C, Beard C. Beard's ptosis. Birmingham: Aesculapius Pub. Co.; 1990.

13. Choi CJ, Chou JC, Lefebvre DR, et al. Margin reflex distance: differences based on camera and flash positions. Ophthal 
Plast Reconstr Surg 2015 Apr 3 [Epub]. http://dx.doi.org/ 10.1097/iop.0000000000000456.

14. Flynn TH, Rose GE, Shah-Desai SD. Digital image analysis to characterize the upper lid marginal peak after levator aponeurosis repair. Ophthal Plast Reconstr Surg 2011;27:12-4.

15. Coombes AG, Sethi CS, Kirkpatrick WN, et al. A standardized digital photography system with computerized eyelid measurement analysis. Plast Reconstr Surg 2007;120:647-
56.

16. Zhou M, Jin R, Li Q, et al. Frontalis muscle flap advancement for correction of severe ptosis under general anesthesia: modified surgical design with 162 cases in China. Aesthetic Plast Surg 2014;38:503-9.

17. Hwang K, Kim DJ, Hwang SH. Insertion of frontalis muscle relating to blepharoptosis repair. J Craniofac Surg 2005;16: 965-7. 